\section{Zentrifugalbeschleunigung, relative}

W. G. Guder

München, Deutschland

Englischer Begriff relative centrifugal force

Definition Die relative Zentrifugalbeschleunigung stellt die Zentrifugationskraft als Vielfaches der Erdbeschleunigung dar.

Beschreibung Die Fähigkeit einer $\triangleright$ Zentrifuge, Teilchen oder Moleküle zu sedimentieren, hängt von der Umdrehungs- zahl pro min (n), dem Schleuderradius (r) vom Mittelpunkt bis zum Boden des zu zentrifugierenden Materials (Bechers, Röhrchens) und von der Zeit der Zentrifugation ab. Diese wird als relative Zentrifugalbeschleunigung (abgekürzt mit einem kursiven $g$ ) wie folgt berechnet:

$$
g=11,19 \times \mathrm{r} \times(\mathrm{n} / 1000)^{2}=1,119 \times 10^{-5} \times \mathrm{r} \times \mathrm{n}^{2}
$$

\section{Literatur}

Hallbach J (2001) Klinische Chemie für den Einstieg. Thieme, Stuttgart 